\title{
Pain on injection of epidural bolus doses in patient with chronic metastatic pain
}

Tihana Magdić Turkovic, MD, PhD, Ivan Ivanovski, MD, Sanja Ćosić, MD, prim. Marinko Vučić, MD, PhD University Hospital Center "Sestre milosrdnice", Department of anesthesiology, intensive care medicine and pain management

\section{INTRODUCTION}

Pain during the application of epidural therapy is very unspecific und uncommon sing. It is usually classified under mechanical catheter complications. Mechanical complications and superficial infections in the study of Smith et all. occurred in as many as $43 \%$ of patients and deep infections including epidural abscesses occurred in $13 \%$ of the patients $(1,2)$.

\section{CASE REPORT}

We present a 77 year old caucasian male patient with bone metastasis of prostate cancer, who was referred to our Ambulance for Pain Management for pain in the left hip, lumbar region and leg. Because of high pain scores and the risk of high opioid doses side effects epidural catheter was placed. First epidural catheter was placed in the L3/4 interspace. The catheter itself and its insertion point had been changed every 3-4 weeks (due to the displacement of the tip of the epidural catheter and consequently the ineffectiveness of the drugs given via the epidural catheter or to prevent infection of the insertion site and epidural space). All catheters were inserted under aseptic conditions, through an 18-gauge Tuohy needle using the loss of resistance technique. The patient had self-administered premixes solution of analgesics (fentanyl and bupivacaine) at home in the form of intermittent boluses $(8 \mathrm{ml}, 2-3 x /$ day $)$. With time, dosages of epidural boluses were getting higher, with max. dosage of $10 \mathrm{ml} 4$ times daily of a premixed solution. Four months after the start of epidural analgesia patient developed incontinence (possible related to cancer?), but was pain free. Six months after the application of epidural catheter patient started to feel pain during the application of epidural boluses. At that time the patient was afebrile, without any neurological deficit, and insertion point of the catheter was clear. We replaced the catheter on another level. After that, there was no more pain during epidural application. Urinary incontinence was still present, but no other neurological impairments were noticed. Two weeks after the mentioned control, diluted blood started to present in the epidural catheter which resolved with another repositioning of the catheter. The pain during applications of epidural bolus doses was present all the time. There were no signs of infection and the patient was still afebrile. During the last 10 days of his life the epidural boluses were completely ineffective. He died seven months after the first epidural catheter placement due to cancer progression and multiple organ failure (renal failure, pneumonia). A few days before he died epidural puncture spot was inflamed, infected and with pus (in contrast to the last control 12 days earlier, when the puncture point was clean, without any signs of infection), so the epidural catheter was completely removed. The MRI or other imagine studies were not performed, neither was postmortem autopsy.

\section{DISCUSSION}

There is no statistically relevant research on epidural application pain. With literature research we found that possible causes of this pain are catheter tip fibrosis, granuloma formation and spinal epidural abscess (SEA). Catheter tip fibrosis and granuloma are most commonly associated with long term morphine epidural analgesia and it is relatively benign (3). We didn't use morphine, already bupivacaine. SEA is a rare but lifethreatening complication of epidural analgesia. Smith et al. in their research on complications of chronic epidural analgesia had 8 cases of pain on the application of epidural therapy and in $4(50 \%)$ they had diagnosed SEA (2). In another paper, Smith et al. described a case series of 11 patients with SEA complicating chronic epidural analgesia and state that most specific and earliest sign was pain on the epidural application of drugs, but because of low number of patients they couldn't do statistical analysis (3).
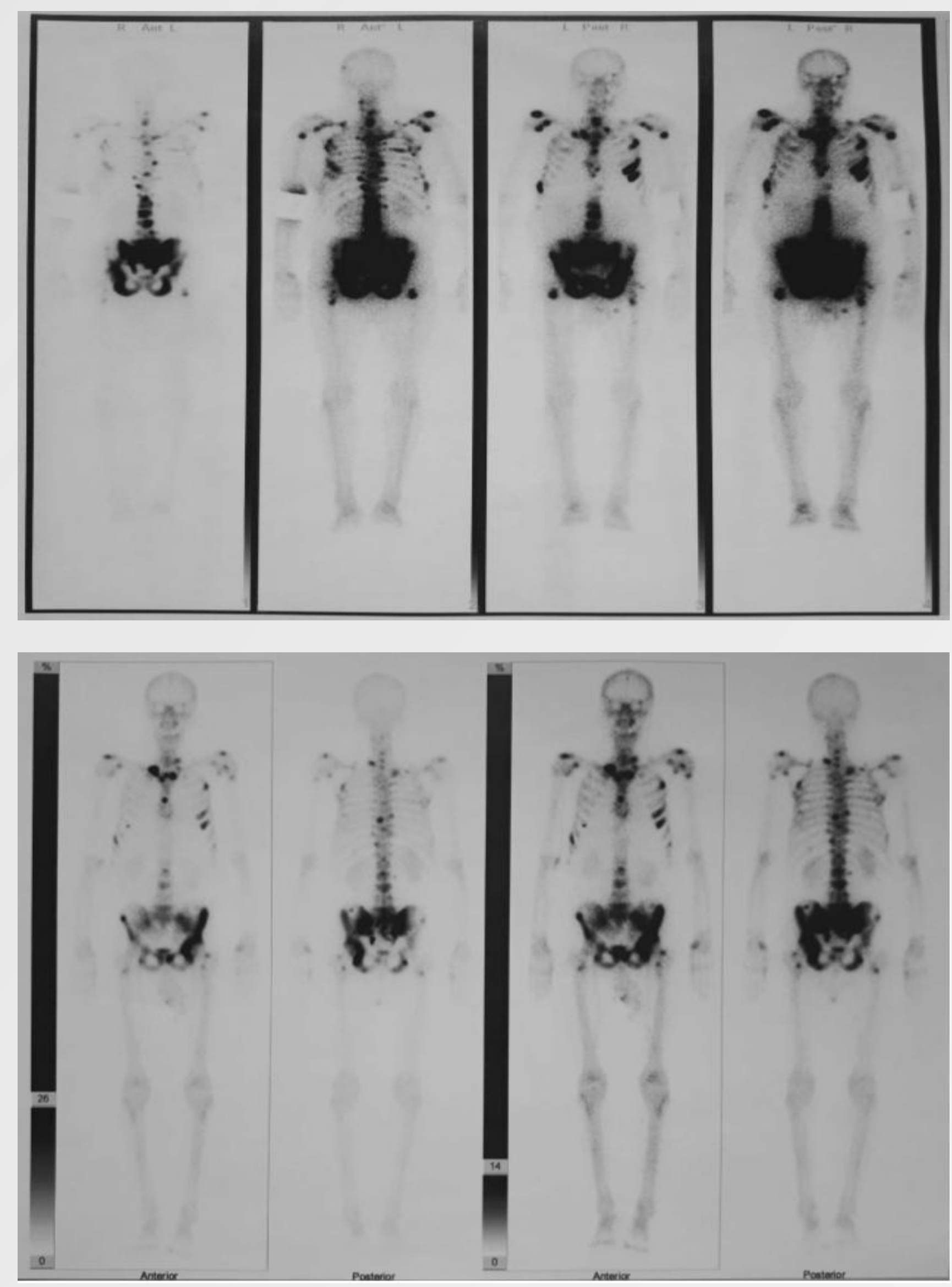

Figure 1. Patient bone scintigraphy showing multiple, in places confluating spots of intensive to very intensive radioisotop accumulation in face bones both shoulders, both elbows, left underarm, both clavicles, sternum, both scapulas,,ribs, spine, all bones of the pelvis and proximal parts of both femurs.

\section{CONCLUSION}

The classical triad of SEA is fever, spinal pain and neurological deficit, but rarely all three occur together. Usually, the symptoms are not specific at the beginning (weakness and fever) but slowly progress from spinal pain to neurologic deficit, paresthesias and paraplegia when the disease is usually irreversible (4). Catheter tip fibrosis and granuloma formation should always be considered in the differential diagnosis of SEA (3). High awareness for SEA of the physician performing or attending epidural analgesia is crucial for early recognition and proper treatment of this life-threatening disease. We believe that pain on the application of epidural therapy should awake suspicion in attending physician on SEA.

\section{Literature:}

1. Tay W, Ho KY, The Role of Interventional Therapies in Cancer Pain Management, Ann Acad Med Singapore 2009;38:989

2. Smitt PS, Tsafka A Outcome and Complications of Epidural Analgesia in Patients with Chronic Cancer Pain. Cancer 1998;83:2015-22.

3. Smitt PS, Tsafka A et all.Spinal epidural abscess complicating chronic epidural analgesia in 11 cancer patients: clinical findings and magnetic resonance imaging. J Neurol (1999) 246 : 815-820 4. https://www.uptodate.com/contents/spinal-epidural-

abscess?search=spinal\%20epidural\%20abscess\&usage_type=default\&source=search_result\&sele ctedTitle $=1 \sim 89 \&$ display_rank=1 